\title{
Intersubspecies Hybrids and Their Progeny in Brassica campestris
}

\author{
J. Mitchell McGrath ${ }^{1}$ and Carlos F. Quiros \\ Department of Vegetable Crops, University of California, Davis, CA 95616 \\ Additional index words. Brassica rapa, maternal inheritance, novel variation, turnip, pak-choi, Chinese cabbage, toria
}

\begin{abstract}
Morphology and fertility were characterized for 22 intersubspecies hybrids within $B$. campestris L. Nine subspecies, representing crop types from different geographical areas, were used as pollen donors on three different seed parents. Stability of scored morphological characters was divided into four classes based on their appearance in $F_{1}$ hybrids; i) constant (present in all hybrids when the character was present in one of the parents, e.g., enlarged hypocotyl, divided leaf), ii) variable (present in some hybrids when the character was present in parent types, e.g., petiole color, pubescence), iii) novel (appearing in hybrids but not present in parents, e.g., anther tip spot, selfcompatibility), and iv) reciprocal differences. Constant characters are assumed to have a strong genetic component, variable characters may result from heterozygosity in parents, an allelic series, or polygenic inheritance, and novel characters may arise through mutation or altered gene or physiological interactions. Reciprocal crosses revealed morphological components controlled by the maternal parent, and were most striking in pak-choi (ssp. chinensis) by turnip [ssp. rapifera (Metzg.) Sinsk.] hybrids. Pollen and seed fertility of hybrids was generally reduced when Indian oilseeds [ssp. dichomata (Roxb.) Olsson; ssp. trilecularis (Roxb.) Olsson] were used as parents. Inheritance of the enlarged hypocotyl character was tested in one $F_{2}$ population. Segregation of the enlarged hypocotyl trait was consistent with a hypothesis of a dominant Mendelian locus. Various novel characters appeared in this $F_{2}$ population that were not evident in the parents of the hybrid, some of which also showed Mendelian segregation. Genetic differentiation of nuclear or plastid genomes may account for these observations.
\end{abstract}

Extensive morphological variation prompted early taxonomists to give specific rank to many currently recognized subspecies within B. campestris L. (syn. B. rapa Metzg.) (Bailey, 1930; Prakesh and Hinata, 1980). Subspecific taxa have been generally classified on the basis of crop use, and the range of morphological variation has presumably been influenced by selection for crop types in various regions. Most, if not all, major crop types originated in the Old World; however, their history remains obscure due to cultural and regional crop use differences over a large geographical range (Sinskaia, 1928).

Broadly defined, the major cultivated forms of $B$. campestris $(2 \mathrm{n}=2 \mathrm{x}=20)$ are divisible either morphologically (as turnip, oilseed, or leafy vegetable) or geographically in their initial primary area of cultivation (Europe, India and adjacent northwest areas, and the Far East). Geographically, turnips are found across all three geographic regions, although historically turnips have been more important to European and Asian economies. Primitive Indian turnip types have been found under the name shelgham (U.S. Dept. Agr. National Seed Storage Laboratory, Fort Collins, Colo., personal communication). Oilseeds have been important in all three regions as well, but are taxonomically distinct following geography. European oilseed forms [ssp. olifera (Metzg.) Sinsk.], commonly known as rape or colza (together with B. napus L. oilseed), are the primary B. campestris oilseed types grown in temperate regions. Two types of Indian oilseeds, toria (ssp. dichotoma) and sarson (ssp. trilocularis) can be distinguished by the self-compatibility and the often yellow seed coat of sarson. Ancient Asian cultures likely used an ancestral form of ssp. chinensis (L.) Makino for seedextracted oil (Li, 1969). Leafy vegetables are particularly di-

Received for publication 11 Apr. 1990. We are grateful to V. D'Antonio for technical assistance and D. Bay for photographic assistance. This work was supported by U.S. Dept. of Agriculture competitive grants 86 CRCR-1-1926 and 88-37262-4018 to C.F.Q. The cost of publishing this paper was defrayed in part by the payment of page charges. Under postal regulations, this paper therefore must be hereby marked advertisement solely to indicate this fact,

'Present address and corresponding author: Dept. of Biology, Univ. of Michigan, Ann Arbor, MI 48109-1048. verse in Asia. Pak-choi (ssp. chinensis) and pe-tsai or Chinese cabbage [ssp. pekinensis (Lour.) Olsson] are widely cultivated (Li, 1981). Less common Asian leafy vegetables, which generally find use as pot herbs, include mizuna and mibuna (spp. japonica Sieb., syn. nipposinica Bailey), ssp. parachinensis (Bailey) T. \& L., ssp. narinosa Bailey and spp. utilis T. \& L. In Europe, turnip greens are cultivated, and raab or brocolletto types are grown for their inflorescence. India apparently lacks native leafy vegetable types of $B$. campestris. The basic cultivated varieties are generally easy to identify; however, minor crops and intermediate types present special taxonomic problems.

The genetic basis of morphological differentiation in B. campestris has received some attention; however, much recent work is concerned either with traits within subspecies and crop types (e.g., Dorrell and Downey, 1964; Hawk, 1982; Kadkol et al., 1986; Klein Geltink, 1983; Watanabe, 1981) or identifying markers useful for demonstrating genetic principles (Hawk and Crowder, 1978; Williams and Hill, 1986). Our goal was to construct a series of segregating $\mathrm{F}_{2}$ populations from crosses between various subspecies to investigate the inheritance of agronomically and taxonomically important morphological characters. Adjunctly, we wished also to explore the use of intersubspecies hybrids as sources of novel horticultural combinations in Brassica improvement. The potential for intersubspecies transfer of desirable agronomic traits and exploitation of heterosis was suggested by Olsson (1954), but has not been explored systematically. There has been little effort to use intersubspecies hybridization in Brassica breeding, probably due to diversification of vegetable and oilseed markets and sufficient variability in existing germplasm. While representing a scant proportion of the total B. campestris germplasm, results obtained from 22 combinations of intersubspecies hybrids are presented as an example of the extremes that may be encountered in using intersubspecies hybrids for $B$. campestris crop improvement.

\section{Materials and Methods}

Three accessions (listed in Table 1) were used as female parents: pak-choi, turnip, and toria. Pollen from each of the nine 
accessions in Table 1 was applied to the immature stigmas of each female plant. Bud pollinations were performed exclusively to minimize S-allele-mediated incompatibility reactions. Reciprocal crosses in all combinations (using the same plants as both male and female) were performed between pak-choi, turnip, and toria. For convenience, crosses are referred to by their common names. In the text, hybrids enclosed within quotation marks indicate the direction of the cross (i.e. 'female $x$ male'). Otherwise, hybrids of both directions are discussed. Hybrids were confirmed by morphology and isozyme analyses as per Quiros et al. (1987). Glutamate-oxaloacetate transaminase (GOT) was assayed as described by Douches and Quiros (1988).

Two hybrids from each cross. were grown and analyzed for differences in morphology and fertility. Plants were grown at the same time and in the same greenhouse (to minimize environmental variation), in 3.8-liter pots containing $40 \%$ sand, $50 \%$ peat moss, and $10 \%$ topsoil ( $\mathrm{pH}$ adjusted to 6.2 to 6.8 with lime). Generally, the greenhouse was at 22 to $24 \mathrm{C}$ day and $13 \mathrm{C}$ night; however, days during the summer occasionally reached $28 \mathrm{C}$. When required, vernalization was accomplished by placing plants at 5C for 6 weeks in a growth chamber (Vander Meer and Van Dam, 1984). Male fertility was assessed as the proportion of $>500$ pollen grains from at least two separate flowers that stained with $1 \%$ acetocarmine. When possible, pollen was collected at multiple times throughout flowering. Female fertility was assessed at the end of flowering as the number of wellformed seeds per well-developed silique resulting from controlled self-pollinations. For statistical comparisons of means between $B$. campestris hybrids, a nonpairing $t$ test was performed. An additional five plants of each hybrid were grown in the field to confirm the stability of morphological characters.

A segregating $\mathrm{F}_{2}$ population of 61 plants was derived from a single self-compatible $F_{1}$ hybrid plant from the cross between turnip (cv. Yorii Spring as female) and 'Kwan Hoo Choi' (mok pak-choi as male). Analysis of segregating characters was accomplished with the LINKAGE-1 program (Suiter et al., 1983). In cases where inheritance was tested under dihybrid hypotheses, segregation $\chi^{2}$ values were computed manually.

\section{Results}

All hybridizations between different $B$. campestris subspecies were successful, although seed set varied. Two to 10 pollinations for each cross yielded a low of four $F_{1}$ seeds (six pollinations, 0.7 seeds per silique) in the case of 'pak-choi $\times$ toria', to a high of 95 seeds (seven pollinations, 13.6 seeds per silique) from 'pak-choi $\times$ Kwan Hoo Choi'. Table 2 shows the mean number of seeds per well-developed silique obtained from crosses between different subspecies. Seed set with crosses involving toria were generally reduced compared with other cross combinations. Seed set from self-pollinations was reduced as well, perhaps due to self-incompatibility or associated factors.

Growth and vigor of the hybrids were generally similar to the parent types. Heterosis (i.e., hybrid vigor) in most subspecies hybrid combinations was not readily apparent. Plants of 'turnip $x$ sarson' and 'toria $\times$ mizuna' were weak, failed to flower, and died soon after vernalization. The exception were plants of 'turnip $\times$ Chinese cabbage', which copiously produced large, long leaves (Fig. 1). A similar turnip $\times$ Chinese cabbage hybrid is commercially available (Werner, 1984).

Morphology of $F_{1}$ hybrids. Morphology of $\mathrm{F}_{1}$ hybrids was generally intermediate between their respective parental types. Within an $F_{1}$ population, each hybrid was usually similar to its siblings, and little or no segregation for morphological characters was observed. While an exhaustive analysis of morphological characters was not performed, some interesting relationships were evident. These relationships were of four general types, i) parental characters always expressed in their respective hybrids (stable characters), ii) parental characters expressed in some but not all respective hybrids (variable characters), (iii) characters expressed in hybrids but not their respective parents (novel characters), and (iv) differences in reciprocal crosses.

Constant characters. When turnip was used as one parent, the fleshy root character (botanically an enlarged hypocotyl) was observed in all $F_{1}$ plants. Root size was generally reduced with respect to turnip. Similarly, the divided leaf phenotype of mizuna was evident in all of its hybrids, but intermediate to that of mizuna (Fig. 1). A common leaf morph in B. campestris, lyrate leaf shape, appeared in most crosses in which one partner had this character (e.g., toria, sarson, raab, and turnip rape). These characters were similar and fully penetrant among siblings of the same cross and between different crosses. Sarson's yellow seed character never appeared in hybrids, and $F_{1}$ hybrids involving sarson were self-incompatible.

Variable characters. Petiole thickness varied with the male parent when pak-choi was used as the female parent. The petiole was wide like pak-choi in crosses involving Chinese cabbage, 'Kwan Hoo Choi', toria, raab, and turnip but thin using mizuna, turnip rape, or sarson as the male parent. Also, when pak-choi

Table 1. List of $B$. campestris subspecies used.

\begin{tabular}{|c|c|c|c|c|c|}
\hline Subspecies & Cultivar & $\begin{array}{c}\text { Common } \\
\text { name }^{z}\end{array}$ & Area $^{y}$ & $\begin{array}{c}\text { Accession } \\
\text { no. }\end{array}$ & Source $^{x}$ \\
\hline chinensis & Lei Choi & Pak-choi & $A$ & B489 & $\mathrm{L}$ \\
\hline parachinensis & Kwan Hoo Choi & 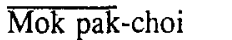 & A & $\mathrm{B} 233$ & $\mathrm{RC}$ \\
\hline japonica & Mizuna & -- & $\mathrm{A}$ & B487 & JSS \\
\hline pekinensis & Matsushima & Chinese cabbage & A & B488 & JSS \\
\hline rapifera & Yorii Spring & Turnip & A & B493 & JSS \\
\hline olifera & Torch & Turnip rape & $\mathrm{E}$ & $\mathrm{B} 200$ & $\mathrm{DC}$ \\
\hline -- & - & Raab & $\mathrm{E}$ & -- & $\mathrm{HM}$ \\
\hline dichotoma & -.. & Toria & I & 1390 & $\mathrm{DC}$ \\
\hline trilocularis & & Yellow sarson & I & 1404 & $\mathrm{DC}$ \\
\hline
\end{tabular}

${ }^{2}$ Underscore designates accession used as both female and male parent.

yArea: $\mathrm{A}=$ Asian; $\mathrm{E}=$ European; $\mathrm{I}=$ Indian

${ }^{\times} \mathrm{DC}=\mathrm{D}$. Cohen, UC Davis (numbers preceded by DC77-; (except B200); HM = Harris Moran Seed Co., Rochester, N.Y.; L = Lockhart Seed Co., Stockton, Calif.; JSS = Johnny's Selected Seeds, Albion, Maine; RC = Redwood City Seed, Co., Redwood City, Calif. 
Table 2. Number of well-developed $F_{1}$ hybrid seed per silique recovered from intersubspecies pollinations.

\begin{tabular}{|c|c|c|c|}
\hline \multirow[b]{2}{*}{ Male parent } & \multicolumn{3}{|c|}{ Female parent ${ }^{\mathbf{z}}$} \\
\hline & Pak-choi & Turnip & Toria \\
\hline & \multicolumn{3}{|c|}{ Seeds/filled silique (mean) } \\
\hline Turnip rape & (3.6) & $(6.2)$ & $15 / 6$ \\
\hline Pak-choi & (4.6) & $(6.5)$ & + \\
\hline Chinese cabbage & $60 / 6 \quad(10.0)$ & $(8.0)$ & + \\
\hline Kwan Hoo Choi & $95 / 7 \quad(13.6)$ & $(8.6)$ & Not crossed \\
\hline Mizuna & $(3.2)$ & $20 / 2 \quad(10.0)$ & $15 / 6 \quad(2.5)$ \\
\hline Toria & $(0.7)$ & $(4.3)$ & $28 / 31 \quad(0.9)$ \\
\hline Sarson & $(4.8)$ & $(6.7)$ & $25 / 5$ \\
\hline Raab & + & Not crossed & $(0.4)$ \\
\hline Turnip & $32 / 4 \quad(8.0)$ & $25 / 9 \quad(2.7)$ & \multirow{2}{*}{$\begin{array}{c}+ \\
2.3\end{array}$} \\
\hline Mean seeds per silique & 6.1 & 6.6 & \\
\hline
\end{tabular}

$z_{+}=$seeds obtained but number of siliques not available.

was a parent, petiole color (white like pak-choi or green) varied among siblings as well as among different hybrids, but in no readily discernible pattern. Leaf surface pubescence appeared in most $F_{1}$ hybrids when one parent was also pubescent (e.g., Chinese cabbage, sarson, raab, and turnip rape). However, the two 'toria $\times$ turnip rape' hybrid individuals differed for the presence of this trait. Variation in seed size of the hybrids was also 'noted but not quantified, and was evident between progeny of the same cross.

Novel characters. Novel characters were evident in three cases. First was one 'toria $\times$ pak-choi' individual; a spot of anthocyanin pigment was observed at the tip of each anther. This plant also differed from its sibling in both shape and size of the leaf. Anther tip pigmentation was shown to be a dominant character in B. campestris by Cours (1977). Second was the appearance of a single self-compatible 'turnip $\times$ Kwan Hoo Choi' hybrid. Self-compatibility was assessed by a high proportion of seedfilled siliques on each raceme, yielding $>3000$ seeds from this plant. Third, petioles were attached to the swollen hypocotyl in hybrid 'pak-choi $\times$ turnip' plants, but not in the reciprocal combination (Fig. 2).

Reciprocal differences. Reciprocal differences in morphology were observed in the three cases where crosses were done in both directions (Fig. 2). A strong maternal component of leaf morphology and color was seen in reciprocal hybrids involving turnip and pak-choi. 'Turnip $\times$ pak-choi' showed slender green petioles and longer, thinner, light-green leaf blades characteristic of turnip, while 'pak-choi $\times$ turnip' had thick white petioles and shorter, rounder, dark-green leaf blades more similar to pakchoi. In 'toria $\times$ pak-choi' and the reciprocal, neither direction tended to resemble the parents, except for a wide petiole when using pak-choi as a seed parent. In the latter hybrid, siblings were morphologically distinct from one another. Hybrid 'toria $\times$ turnip'. and the reciprocal were morphologically similar, but in both cases they more closely resembled toria. Reciprocal differences were evident in the arrangement of leaflets on the petiole and in the characteristics of the leaf margin (Fig. 2); however, these phenotypes were difficult to ascribe to a particular parent.

Flowering behavior. In B. campestris, flowering behavior can be roughly divided into annual and biennial habits, and variation for flowering habit can be found within some subspecies. In biennial forms, flowering can be induced with low temperature, and different cultivars may require a short or lengthy period of vernalization to initiate flowering (Vander Meer and Van Dam, 1984). For instance, under our field conditions, turnip flowered earlier than pak-choi (data not shown); hence, turnip may be regarded as weakly biennial relative to pak-choi. Under greenhouse conditions, parental accessions exhibiting the biennial habit had not flowered after 18 weeks, and were vernalized. All annual accessions had flowered by this date. By extension, $F_{1}$ hybrids were treated in a similar manner, i.e., hybrids failing to flower in the greenhouse 18 weeks after plant-

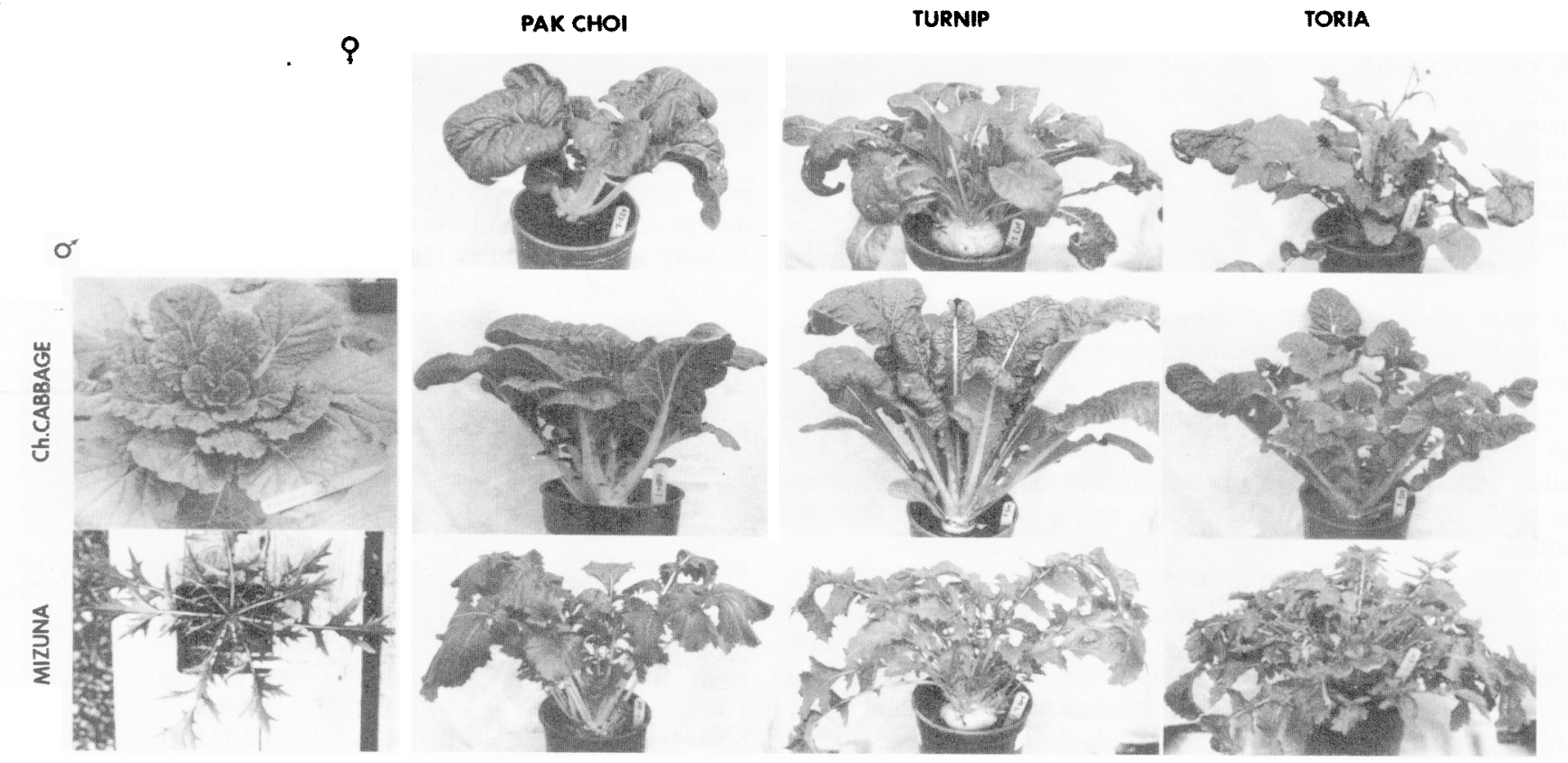

Fig. 1. Morphology of parental plants and their $F_{1}$ hybrids. Seed parents are shown in the top row. Pollen donors are in first column. Respective hybrid plants complete the table. Shown is Chinese cabbage cv. Wong Bok. This cultivar is similar to 'Matsushima' used as a pollen donor but produces a rounder head than does 'Matsushima'. 


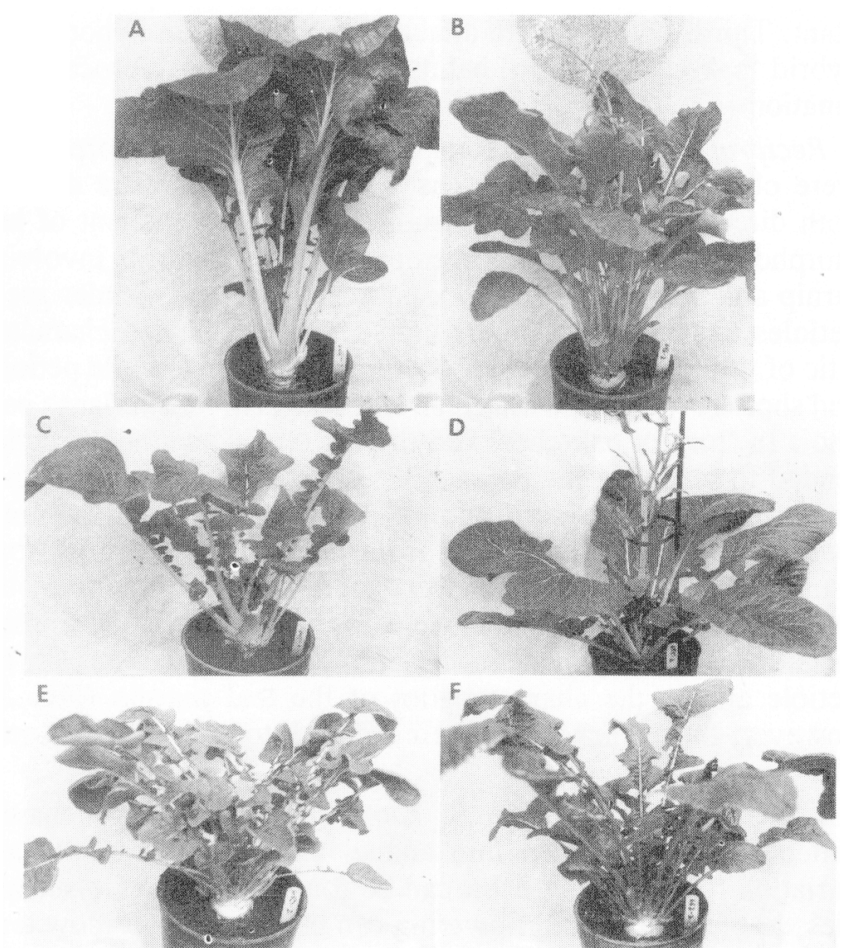

Fig. 2. Reciprocal differences in $F_{1}$ hybrids: (A) 'Pak-choi $x$ turnip'; (B) 'Turnip $\times$ pak-choi'; (C) 'Pak-choi $x$ toria'; (D) 'Toria $\times$ pakchoi'; (E) 'Turnip $\times$ toria'; (F) 'Toria $\times$ turnip'.

Table 3. Flowering behavior of $F_{1}$ intersubspecies hybrids. $A=$ annual, $\mathrm{B}=$ biennial. $\mathrm{A} / \mathrm{B}$ indicates both types recovered in hybrids. No distinction is made between weak and strong biennial flowering habit (see text).

\begin{tabular}{lccc}
\hline & \multicolumn{3}{c}{ Female parent } \\
\cline { 2 - 4 } Male parent & Pak-choi (B) & Turnip (B) & Toria (A) \\
\hline Turnip rape (A) & A & A/B & A \\
Pak-choi (B) & B & A & A/B \\
Chinese cabbage (B) & B & B & A/B \\
Kwan Hoo Choi (A) & A & A & Not crossed \\
Mizuna (B) & B & B & Died \\
Toria (A) & A & A/B & A \\
Sarson (A) & A & Died & A \\
Raab (A) & A & Not crossed & A \\
Turnio (B) & B & Died & B
\end{tabular}

ing were vernalized and thus considered biennial. Within this set of restrictive conditions the following relationships were observed:

1) The flowering behavior expressed in hybrids made with pak-choi as the seed parent always showed the habit of the pollen donor (Table 3). Hybrids were consistently annual when the pollen donor was annual. Thus, using pak-choi as female, it appeared that annual habit was dominant to biennial.

2) With both turnip and toria as seed parents, examples were encountered where one hybrid sibling was annual and the other required vernalization (Table 3 ). One explanation may be that annual and biennial habits are segregating in these cases. More likely, experimental discrimination between weakly biennial (e.g., turnip) and strongly biennial (e.g., pak-choi) habits was insufficient, and response to the length of vernalization treatment and number of days to flowering after vernalization may represent variable characters.
3) A reciprocal difference in flowering behavior was observed. Hybrid 'pak-choi $\times$ turnip' was biennial but 'turnip $\times$ pak-choi' was annual (Table 3). Both parents were biennial under these conditions.

4) Crosses within individual accessions (i.e., pak-choi selfed and toria selfed) did not deviate from their normal flowering habit.

Pollen fertility of $F_{l}$ hybrids. The portion of stainable pollen of intersubspecies $F_{1}$ hybrids ranged from $48.0 \%$ ('toria $\times$ raab') to $97.3 \%$ ('pak-choi $\times$ Chinese cabbage') (Table 4). Generally, pollen fertility values showed little variation between individuals of a particular cross (Table 4). High variation was due either to differences between individuals (e.g.., 'pak-choi $\times$ toria' and 'turnip $\times$ toria'), differences in values from the same plant taken at different collection times (e.g., 'toria $\times$ turnip rape'), or both (e.g., 'pak-choi $\times$ turnip rape'). Reasons for these patterns of variation were not clear, but temporal variation may have an environmental component. Alternatively, Stout (1922) characterized a physiological reduction in vigor (i.e., fertility) during the transitions from vegetative to reproductive growth and from flowering to senescence in pak-choi and Chinese cabbage, termed cyclic fertility. For hybrids analyzed here, whose fertilities had been determined on three or four separate occasions, no clear trend of a cyclic effect on pollen fertility was evident.

The influence of female accession on pollen fertility of $F_{1}$ hybrids was assessed as an average response across all pollen donors (i.e., fertilities of seed parents were summed across all pollen donors). The average response of turnip (79.5\%) was not significantly different when compared with pak-choi $(87.9 \%)(t$ $=1.59$, df $=13)$ or toria $(t=1.07$, df $=10)$. However, the average response of toria $(71.7 \%)$ was significantly less than of pak-choi $(t=2.72$, df $=13)$. Thus, on average, hybrids involving toria as the seed parent showed reduced pollen fertility compared with hybrids with pak-choi, but not turnip, as seed parents. Paradoxically, individual crosses between pak-choi and toria showed greater fertility than crosses between turnip and toria. Pollen fertility in selfed toria was uniformly low when sampled from different branches and at different times during flowering and may have been an example of inbreeding depression, as fertility was $94.4 \%$ in the parent toria plant.

A reciprocal difference in pollen fertility was noted between pak-choi $\times$ turnip hybrids (Table 4 ). Pak-choi as female exhibited good fertility with turnip as the pollen parent $(95.9 \%)$, but fertility was reduced in the reciprocal combination $(69.6 \%)$.

Seed fertility of $F_{I}$ hybrids. At least one plant per hybrid

Table 4. Pollen stainability of $F_{1}$ intersubspecies hybrids.

\begin{tabular}{lccc}
\hline \hline & \multicolumn{4}{c}{ Female parent $^{\mathbf{z}}$} \\
\cline { 2 - 4 } Male parent & Pak-choi & Turnip & Toria \\
\hline Turnip rape & $70.9(11.7)$ & $82.7^{y}$ & $78.9(9.3)$ \\
Pak-choi & $87.0(0.4)$ & $69.6(4.1)$ & $85.6^{\mathrm{y}}$ \\
Chinese cabbage & $97.3(0.6)$ & $84.6(2.3)$ & $82.9(5.9)$ \\
Kwan Hoo Choi & $91.2(4.5)$ & $95.4(0.5)$ & Not crossed \\
Mizuna & $95.8(2.8)$ & $87.6^{\mathrm{y}}$ & Died \\
Toria & $90.0(9.4)$ & $64.4(14.8)$ & $51.8^{\mathrm{y}}$ \\
Sarson & $75.0(2.6)$ & Died & $65.7(6.4)$ \\
Raab & $88.0(2.4)$ & Not crossed & $48.0^{\mathrm{y}}$ \\
Turnip & $95.9(0.4)$ & Died & $69.0(6.6)$ \\
Mean (std. dev.) & $87.9(9.3)$ & $79.5(11.1)$ & $71.7(14.0)^{\mathbf{x}}$ \\
\hline
\end{tabular}

zPercent (std. dev. between pairs of $F$, hybrids).

${ }^{y}$ Value was determined for only one hybrid plant.

xToria selfed was excluded to avoid bias due to its low measure. 
combination was selfed to obtain $\mathrm{F}_{2}$ seed for subsequent genetic analysis. Based on the number of well-formed and presumably viable seeds recovered from eight to 96 filled siliques per hybrid plant, female fertility of $F_{1}$ hybrids ranged from 0.0 seeds per silique ('pak-choi $\times$ sarson') to 10.9 ('pak-choi $\times$ Chinese cabbage') (Table 5). Seed set was variable between individuals of a particular hybrid combination when both individuals were selfed (data not shown), and was presumably influenced by both the male fertility of that plant and the environmental conditions at the time of pollination; for this reason, statistical comparisons were not appropriate. Seeds obtained by selfing 'pak-choi $\times$ sarson' hybrids were shrunken and inviable but their siliques were well-developed. Whether this hybrid combination is crosssterile remains to be determined. Reciprocal differences in seed set occurred between pak-choi $\times$ turnip and turnip $\times$ toria.

Genetic analysis of morphological characters in one $F_{2}$ population. The inheritance of the enlarged hypocotyl (i.e., fleshy root) characteristic of turnip was of interest since it appeared to be a stable character in $\mathrm{F}_{1}$ hybrids and we observed the presence of this character to be variable in two small seed-derived populations of shelgham, an Indian turnip (data not shown). Enlarged hypocotyl and seven other readily scored morphological characters were analyzed in an $\mathrm{F}_{2}$ population of 60 plants derived from the single self-compatible $\mathrm{F}_{1}$ 'turnip $\times$ Kwan Hoo Choi' hybrid. Two characters, enlarged hypocotyl and stemclasping lower leaves, were observed in the turnip parent, and enlarged hypocotyl was also observed in the $\mathrm{F}_{1}$ (Fig. 3). Six additional characters were novel traits that were not apparent in either parent or the $F_{1}$ hybrid. These included a light-green, virescent phenotype, cupped flower petals, inflated siliques (Fig. 3), male sterility (shrunken anthers), female sterility (failure to set open-pollinated seed), and accumulation of anthocyanin in the stem. The virescence character always co-segregated with a labile form of Got-1. The inheritance of flowering habit could not be determined despite the difference between flowering habit of the parents. All $\mathrm{F}_{2}$ plants were annual. Also, while the $\mathrm{F}_{1}$ hybrid displayed self-compatibility with virtually all siliques per raceme filled, $\mathrm{F}_{2}$ plants were self-incompatible, as the number of seed-filled siliques was low and variable on different racemes. Although controlled crosses specifically testing female fertility were not performed, this population was grown at high density and flowers from each plant were in contact with at least four other plants. Under these conditions, all plants, except those scored as female sterile, had set some seed.

Segregation of morphological characters was tested for a sin-

Table 5. Female fertility of $F_{1}$ intersubspecies hybrids expressed as the number of well-formed seeds per silique from self-pollinations.

\begin{tabular}{lcccccc}
\hline \hline Male parent & \multicolumn{5}{c}{ Female parent } \\
\cline { 2 - 7 } & \multicolumn{4}{c}{ Pak-choi } & \multicolumn{3}{c}{ Turnip } & Toria \\
\hline & \multicolumn{1}{c}{ No. seeds/no. siliques with seeds (seeds per silique) } \\
Turnip rape & $127 / 69$ & $(1.8)$ & $169 / 67$ & $(2.5)$ & $146 / 31$ & $(4.7)$ \\
Pak-choi & \multicolumn{1}{c}{ Not selfed } & $95 / 92$ & $(1.0)$ & $115 / 69$ & $(1.7)$ \\
Chinese cabbage & $315 / 29$ & $(10.9)$ & $183 / 43$ & $(4.3)$ & $65 / 28$ & $(2.3)$ \\
Kwan Hoo Choi & $105 / 67$ & $(1.6)$ & $692 / 77$ & $(9.0)$ & Not crossed \\
Mizuna & $310 / 52$ & $(6.0)$ & $40 / 13$ & $(3.1)$ & Died \\
Toria & $175 / 71$ & $(2.5)$ & $133 / 26$ & $(5.1)$ & Not selfed \\
Sarson & $0 / 8^{2}$ & $(0.0)$ & Died & $73 / 32$ & $(2.3)$ \\
Raab & $197 / 96$ & $(2.1)$ & Not crossed & $16 / 29$ & $(0.6)$ \\
Turnip & $513 / 72$ & $(7.1)$ & Died & $50 / 48$ & $(1.0)$ \\
Mean (std. dev.) & $4.0(3.6)$ & $4.2(2.8)$ & $2.1(1.4)$ \\
\hline
\end{tabular}

${ }^{z}$ More than 50 pollinations were performed.

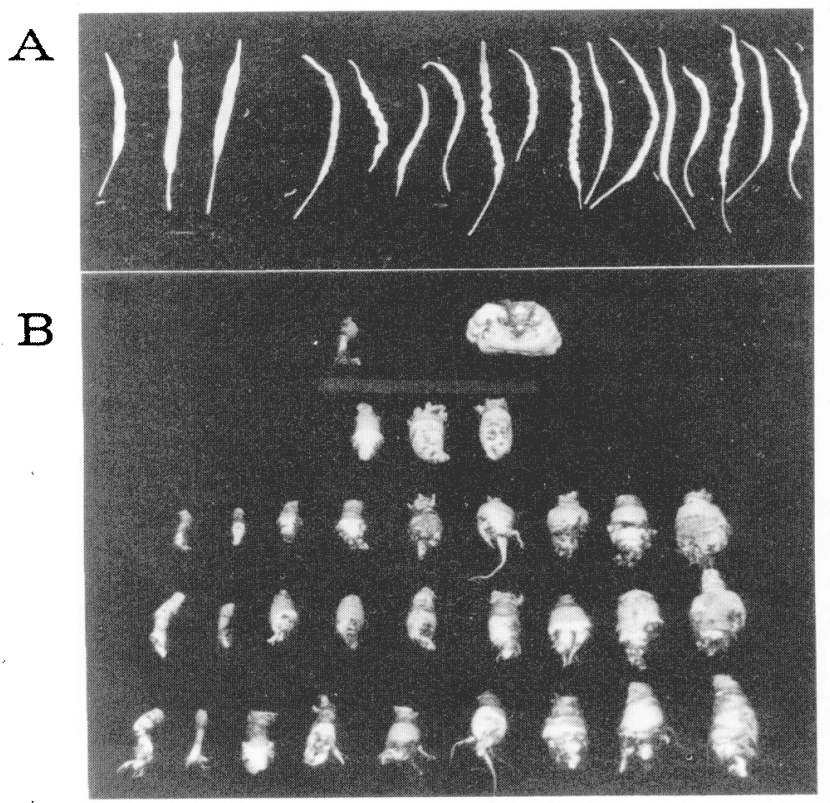

Fig. 3. Examples of $F_{2}$ character segregation: (A) Novel inflated silique character not observed in parents or $F_{1}$ hybrid. Three siliques on left are the recessive phenotype. (B) Enlarged hypocotyl at 22 weeks after planting. Top row: 'Kwan Hoo Choi' (left) and turnip (right) parental phenotypes. Second row: three $F_{1}$ roots. Bottom three rows: Examples from the $F_{2}$ segregating population. This six roots at far left wre scored as the recessive phenotype.

Table 6. Segregation of morphological characters from the $F_{2}$ population derived from 'turnip $\times$ Kwan Hoo Choi'.

\begin{tabular}{|c|c|c|c|c|}
\hline Character & Observed ${ }^{z}$ & Expected & $x^{2}$ & Prob. \\
\hline \multirow[t]{2}{*}{ Enlarged hypocotyl } & $48: 12$ & $3: 1$ & 0.80 & 0.37 \\
\hline & & $13: 3$ & 0.01 & 0.85 \\
\hline \multirow[t]{2}{*}{ Clasping leaf } & $48: 12$ & $3: 1$ & 0.80 & 0.37 \\
\hline & & $13: 3$ & 0.01 & 0.85 \\
\hline \multirow[t]{2}{*}{ Cupped petal } & $52: 9$ & $3: 1$ & 3.42 & 0.07 \\
\hline & & $13: 3$ & 0.40 & 0.50 \\
\hline \multirow[t]{2}{*}{ Male sterility } & $50: 11$ & $3: 1$ & 1.58 & 0.21 \\
\hline & & $13: 3$ & 0.002 & 0.90 \\
\hline \multirow[t]{2}{*}{ Seed sterility } & $38: 15$ & $3: 1$ & 0.31 & 0.58 \\
\hline & & $13: 3$ & 2.58 & 0.10 \\
\hline \multirow[t]{2}{*}{ Inflated silique } & $31: 7$ & $3: 1$ & 0.88 & 0.35 \\
\hline & & $13: 3$ & 0.003 & 0.90 \\
\hline \multirow{2}{*}{ Virscence (and GOT) ${ }^{y}$} & $52: 9$ & $3: 1$ & 3.42 & 0.07 \\
\hline & & $13: 3$ & 0.40 & 0.50 \\
\hline \multirow[t]{2}{*}{ Anthocyanin stem ${ }^{x}$} & $24: 35$ & $3: 1$ & 37.08 & $<0.01$ \\
\hline & & $7: 9$ & 0.19 & 0.65 \\
\hline
\end{tabular}

${ }^{\mathrm{z}}$ Characters are recessive (except enlarged hypocotyl).

y Glutamate oxaloacetate transaminase (GOT).

'Observed anthocyanin accumulation in stem was 24 purple : 35 green.

gle gene model. All characters tested, with the exception of anthocyanin accumulation in the stem, fit the classic 3:1 Mendelian segregation ratio (Table 6). As gene interaction may explain the occurrence of novel characters, inheritance of these characters was consistent with a 13:3 dihybrid segregation ratio as well (i.e., 13 A-B-, A-bb, aabb: 3 aaB-). However, discrimination between 3:1 monogenic and 13:3 digenic ratios could not be determined in an $\mathrm{F}_{2}$ population of this size.

Two components of turnip root inheritance were evident in this $\mathrm{F}_{2}$ population, a putative dominant gene governing the presence of an enlarged hypocotyl, and a presumed polygenic com- 
ponent governing root size and shape in the presence of an enlarged hypocotyl (Fig. 3). Presence of an enlarged hypocotyl was scored at three times during the growing period. At 6 and 12 weeks after planting, the score was determined by visual inspection of the root crown. At the end of the experiment (22 weeks), roots were harvested and scores determined for the entire root. In all cases, the score was consistent with a dominant monogenic character. However, the proportion of plants with an enlarged root varied with time (44/60, 42/60, and 48/60 at 6,12 , and 22 weeks, respectively). Superimposed on the presence of an enlarged hypocotyl, root shape and size showed more complex and presumably polygenic inheritance.

Accumulation of anthocyanin fit a 9 green : 7 purple segregation ratio (Table 6). The inheritance of anthocyanin accumulation in stems could be explained by two genes that modify or degrade anthocyanin to a colorless compound when both are present and dominant (i.e., A-B-), but not in other combinations (i.e., A-bb, aaB-, aabb) Consistent with this hypothesis, some siblings of the $F_{1}$ showed the purple stem character, but the $F_{1}$ plant used to generate the $F_{2}$ did not (i.e., the $F_{1}$ was putatively $\mathrm{AaBb})$.

\section{Discussion}

Sinskaia (1927) was one of the first to report fertile "interspecific" hybrids between types that are now recognized as subspecies of B. campestris, i.e., B. campestris, B. chinensis, and others. Hybrids frequently differed from parents in one or more traits, such as vigor and plant height. Sterility and novel variation occurred in $\mathrm{F}_{2}$ generations. Olsson (1954) demonstrated the lack of reproductive isolation within and between B. campestris oilseed and Asian subspecies, but reported a consistent reduction in fertility when using the Indian oilseed sarson but not toria. In contrast, our results suggest toria also may reduce fertility in some hybrid combinations. The reasons for this discrepancy are not clear, but toria is a diverse group in itself, and genotype and environmental interactions may influence fertility. As only two hybrids per cross from a limited number of accessions were analyzed here, testing fertility relationships with different accessions and larger populations may reveal subtle reproductive changes associated with geographical isolation. Analysis of isozyme banding patterns (Denford and Vaughan, 1977) and restriction fragment length polymorphisms (Song et al., 1988a, 1988b) have provided biochemical evidence that suggests the existence of two geographic centers of diversity, Asian and IndoEuropean. The continuity of the Indo-European group may depend on the accessions tested, and, in this regard, diversity within toria accessions needs to be determined. Hybrid vigor exhibited by 'turnip $\times$ Chinese cabbage' but not 'turnip $\times$ pakchoi' or 'pak-choi $\times$ Chinese cabbage' may indicate that the Asian group can be subdivided as well.

To our knowledge, morphological differences correlated with reciprocal crossing between $B$. campestris subspecies have not been previously reported, perhaps because the majority of breeding efforts have concentrated on cultivar improvement within subspecies. In cases where intersubspecies reciprocal crosses have been reported (Olsson, 1954; Sinskaia, 1927), no reciprocal differences were stated. This contradiction may be attributable to morphotypes that may be considered primitive, such as Sinskaia's (1927) material collected from Central Asia and Olsson's (1954) Indian oilseeds, being used as one parent and may have served to mask any reciprocal differences. This trend is evident in our reciprocal crosses involving toria and turnip. Reciprocal differences were greatest with pak-choi and turnip hybrids. The inheritance of petiole characters between pak-choi cultivars showed no reciprocal differences (McCammon and Honma, 1986). Reciprocal differences observed here may relate to differentiation of the pak-choi cytoplasmic genome. Although its cytoplasmic genome has not yet been characterized, Palmer et al. (1983) showed the chloroplast genome of sarson to differ from three other subspecies, indicating that restriction site polymorphism is present in $B$. campestris organelle genomes. Reciprocal differences may also be due to inherited DNA methylation patterns (H. Saedler, personal communication).

All $F_{1}$ hybrids involving turnip developed a swollen hypocotyl, albeit smaller than normal turnips. In the segregating $\mathrm{F}_{2}$ population, enlarged hypocotyl behaved as single dominant gene. A Mendelian ratio for enlarged hypocotyl in progeny from a hybrid between turnip and Chinese cabbage was reported by Ragionieri (1920; cited in Yarnell, 1956). Shape of the root was investigated by Sinskaia (1928), and at least two genes were proposed to account for segregation of root length. Considering the potential for reciprocal differences in B. campestris, genetic analysis of morphological characters should be performed from both reciprocal hybrids.

Novel characters were common among morphological traits scored. The origin of novel variation, defined as variation arising from interspecific crosses that would not be predicted from genetic studies of the parents alone, maybe attributed to at least four causes (Rick, 1967): i) interaction of nuclear genes unaffected by reciprocal crosses, ii) cytoplasmic interaction as shown by unilateral inheritance in reciprocal crosses, iii) latent variation uncovered by inbreeding, and iv) mutation. In self-compatible Brassica species, outcrossing is promoted and latent variation may be expected to be important in the appearance of novel variation. One character observed, inflated siliques, could be an example of latent parental variation as this character is characteristic of pak-choi and sarson. The absolute correlation of virescence with a labile form of Got-1 suggests a biochemical basis of novel variation; however, either pleiotropism or linkage could explain this result. Other novel characters observed here are difficult to rationalize on the basis of single gene control, but may involve gene interaction, such as suppression of a dominant gene B by a dominant gene A. Such a situation might be expected if duplicate genes were common in B. campestris. Genetic analysis of restriction fragment length polymorphisms shows numerous duplicated loci in the $B$. campestris genome (McGrath, 1989). Without following further the inheritance of these novel characters, little can be said about the mechanisms of their appearance, other than their presence in this intraspecific segregating population suggests that the parents have diverged from one another.

Two observations reported here may affect hypotheses of $B$. campestris crop evolution. First, reciprocal differences in hybrids involving pak-choi suggest its diversification from other subspecies tested. One implication is that pak-choi and its relatives were present in Asia before other Asian types, or that some other isolating mechanism prevented intersubspecies gene flow. Concordant with this observation is the presence of novel characters segregating in the 'turnip $\times$ Kwan Hoo Choi' $F_{2}$ population. Second, if one or few genes control the enlarged hypocotyl characteristic of turnip, loss of this character (perhaps repeatedly) might be expected, particularly if pollinations occurred with nonfleshy-rooted, weedy populations. Single gene 
control for enlarged hypocotyl would help explain the lack of this trait in subspecies morphologically similar to turnip but lacking the enlarged hypocotyl.

\section{Literature Cited}

Bailey, L.H. 1930. The cultivated Brassicas. II. Gentes Herbarium 2:211-267.

Cours, B.J. 1977. Genetic studies in Brassica campestris L. MS thesis, Univ. of Wisconsin, Madison.

Denford, K.E. and J.G. Vaughan. 1977. A comparative study of certain seed isoenzymes in the ten chromosome complex of Brassica campestris and its allies. Ann. Bot. 41:411-418.

Dorrell, D.G. and R.K. Downey. 1964. The inheritance of erucic acid content in rapeseed (Brassica campestris). Can. J. Plant Sci. 44:499504.

Douches, D.S. and C.F. Quiros. 1988. Additional isozyme loci in tuber-bearing Solanums: inheritance and linkage relationships. J. Hered. 79:377-384.

Hawk, J.A. 1982. Tight linkage of two seedling mutants in early flowering turnip rape (Brassica campestris). Can. J. Genet. Cytol. 24:475478.

Hawk, J.A. and L.V. Crowder. 1978. Brassica campestris L., a higher plant with potential for teaching genetics. J. Hered. 69:121-124.

Kadkol, G.P., G.M. Halloran and R.H. Macmillan. 1986. Inheritance of siliqua strength in Brassica campestris L.I. Studies of $\mathrm{F}_{2}$ and backcross populations. Can. J. Genet. Cytol. 28:365-373.

Klein Geltink, D.J.A. 1983. Inheritance of leafshape in turnip (Brassica rapa L. partim) and rape (Brassica napus L.). Euphytica 32:361365 .

Li, H-L. 1969. The vegetables of ancient China. Econ. Bot. 23:253260.

Li, C.W. 1981. The origin, evolution, taxonomy and hybridization of Chinese cabbage, p. 3-9. In: N.S. Talekar and T.D. Griggs (eds.). Chinese cabbage. Asian Veg. Res. Dev. Ctr. Tainan, Taiwan.

McCammon, K.R. and S. Honma. 1986. The inheritance of petiole characteristics in pak-choi. Scientia Hort. 28:29-35.

McGrath, J.M. 1989. Generation of monosomic alien addition lines in Brassica and their use in comparative evolutionary studies. PhD Diss., Univ. of California, Davis. (Diss. Abstr. 90-09256.)

Olsson, G. 1954. Crosses within the campestris group of the genus Brassica. Hereditas 40:398-418.
Palmer, J.D., C.R. Shields, D.B. Cohen and T.J. Orton. 1983. Chloroplast DNA evolution and the origin of amphidiploid Brassica species. Theor. Applied Genet. 65:181-189.

Prakash, S. and K. Hinata. 1980. Taxonomy, cytogenetics and origin of crop Brassicas, a review. Opera Botanica 55:1-57.

Quiros, C.F., O. Ochoa, S. Kianian and D. Douches. 1987. Analysis of the Brassica oleracea genome by the generation of B. campestrisoleracea chromosome addition lines. Theor. Applied Genet. 74:758766.

Rick, C.M. 1967. Exploiting species hybrids for vegetable improvement. Proc. 17th Intl. Hort. Congr. 3:217-229.

Sinskaia, E.N. 1927. Gene-systematical investigations of cultivated Brassica. Bul. Applied Bot. and Plant Breeding 17:1-166.

Sinskaia, E.N. 1928. The oleiferous plants and root crops of the family Cruciferae. Bul. Applied Bot. and Plant Breeding 19:1-648.

Song, K.M., T.C. Osborn and P.H. Williams. 1988a. Brassica taxonomy based on nuclear restriction fragment length polymorphism (RFLPs). 1. Genome evolution of diploid and amphidiploid species. Theor. Applied Genet. 75:784-794.

Song, K.M., T.C. Osborn, P.H. Williams. 1988b. Brassica taxonomy based on nuclear restriction fragment polymorphisms (RFLPs). 2. Preliminary analysis of subspecies within $B$. rapa (syn. campestris) and B. oleracea. Theor. Applied Genet. 76:593-600.

Stout, A.B. 1922. Cyclic manifestation of sterility in Brassica pekinensis and B. chinensis. Bot. Gaz. 73:110-132.

Suiter, K.A., J.F. Wendel, and J.S. Case. 1983. Linkage-1: a pascal computer program for the detection and analysis of genetic linkage. J. Hered. 74:203-204.

Vander Meer, Q.P., and R. Van Dam. 1984. Determination of the genetic variation in the effect of temperature and daylength on bolting of Brassica campestris L. Euphytica 33:591-595.

Watanabe, E. 1981. Development of major Chinese cabbage cultivars in Japan, p. 11-27. In: N.S. Talekar and T.D. Griggs (eds.). Chinese cabbage. Asian Veg. Res. Dev. Ctr. Tainan, Taiwan.

Werner, K. 1984. New turnip greens variety wins grower fans. Amer. Veg. Grower 32:16-17.

Williams, P.H., C.B. Hill. 1986. Rapid-cycling populations of Brassica. Science 232:1385-1389.

Yarnell, S.H. 1956. Cytogenetics of the vegetable crops. II. Crucifers. Bot. Rev. 22:81-166. 